\title{
MASCARO. EL CAZADOR AMERICANO, DE HAROLDO CONTI O EL ASALTO A LO ABIERTO
}

Adriana A. Bocchino*

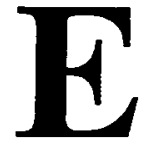

n una escritura de exilios, ${ }^{1}$ Libro de navios y borrascas de Daniel Moyano, un viejo, medio pintor y medio loco, un tal Cont(ard)i, anda buscando a su hijo, en un extraño barco que lleva setecientos desterrados. Su hijo se llama Haroldo y otro desterrado, Rolando, desdoblamiento a su vez de la figura de autor en este texto, ayuda al viejo a buscarlo. ${ }^{2}$ Haroldo, el escritor, puesto que de Haroldo Conti se trata, ha entrado en la difícil indefinición

* Universidade de Mar del Plata.

${ }^{1}$ Escrituras que escriben el exilio en su misma escritura, es decir, fundamentalmente, en sus maneras. Es obvio, puede tratarse, a veces coincidentemente, de historias que hacen referencia a una situación de exilio (autor o personajes), pero esto último no es la condición privilegiada para definir el concepto en un sentido crítico operativo. Véase mi articulo "Exilios y escrituras" en Rev. Celehis (Mar del Plata), n. 5, de próxima aparición.

2 ..."Entonces lo seguí llamando en cuchicheos. Haroldo, ¿estás ahí? [...] me encontré llegando a la cocina. A lo mejor ahí, la cocina "Carelli" de tres hornallas fabricada en Venado Tuerto, la cocina prendida alumbrando con luz de llama, a lo mejor Haroldo ahi encorvado frente a la cocina, porque seguro que mientras siga encendida Haroldo vivirá, las puntas del cabello iluminadas por la leña que arde y sopla, igual que las hojas más altas del álamo carolina cuando reciben en la tarde la última luz del sol"... Daniel Moyano. Libro de navios y borrascas. Buenos Aires: Legasa. 1983, p. 85 . 
de desaparecido. ${ }^{3}$ Y, por lo tanto, su escritura se convierte en una una escritura de desaparecidos, deslizada en esta otra de Daniel Moyano, un exiliado. Desapariciones y exilios constituyen, paradójicamente, la presencia de ciertas escrituras.

En el caso específico de Haroldo Conti, se trata de una marca, la de la desaparición, demasiado fuerte, para el sistema de la literatura argentina, hacia atrás y hacia adelante de su texto Mascaró. El cazador americano. Hacia atrás, porque sólo con dificultad se puede pensar en ciertas escrituras sin ligarlas a destinos personales: destierros, desapariciones, torturas, exilios. Mascaró... es una de ellas. Hacia adelante, porque escrituras y destinos marcarian una seric que bien podria identificarse bajo una retórica determinada.

Esta retórica, hecha de apropiaciones y usos, de escrituras en escrituras, de figuras canonizadas, por una torsión en la que se mezclan escrituras y destinos como dos series paralelas, se refuncionaliza estratégicamente y propone nuevos objetivos. Quizás, pudiese hablarse de una retórica del deslizamiento: una retórica que una vez establecida nos ayude a pensar una genealogía diferente dentro de la literatura argentina y que bien podria ponerse en relación con otras litcraturas.

Ahora bien, si se quisiera decir, en términos genéricos, qué es Mascaró..., podría decirse que es como un cuento, un viaje según las categorías de lo fantástico, o mejor, lo maravilloso. En realidad, las definiciones al respecto interesan poco. Pero sí importa marcar ese aire de cosa común y natural en todo lo que sucede: en el relato y el relato mismo, es decir, en la escritura del relato. Nada parece forzado.

...La vida es una entera travesía, se erraba desde el nacimiento, ese puertito de luces tan recogido, tan breve, suceso pequeño como todo lo que viene después [...]. Todo sucede. La vida es un barco más o menos bonito. ¿De qué sirve sujetarlo? Va y va. ¿Por qué digo esto? Porque lo mejor de la vida se gasta en seguridades. En puertos, abrigos y fuertes amarras. Es un puro suceso, eso digo. ¿Eh, señor Mascaró? Por lo tanto conviene pasarla en celebraciones, livianito. Todo es una celebración...

3..." y Haroldo, que ahora era una semilla plantada en la tierra y que tal vez algún día, de puro obstinado, diese un álamo carolina, un árbol que diese que hablar desde Chacabuco a Bragado por ejemplo. ¿Por arriba? [...] Por allá arriba volando Haroldo con su valijita de cartón, una hermosa y única ala con nervaduras de fresno, luego un instante de vacilación, casi de inmovilidad, la gente que alcanza a ver el girón de tela y el pedalco alocado de las piemas, hasta que, con un giro en barrena, se precipita y se estrella contra la cubierta"... Ibidem, p. 86.

${ }^{4}$ Haroldo Conti. Mascaró. El cazador americano. La Habana: Casa de las Américas. 1975. p. 64-65. 
Oreste Antonelli, el personaje que abre Mascaró..., es un personaje con historia en otros libros del mismo Conti. Algunos ecos pueden seguirse en el narrador de Todos los veranos o en el de Alrededor de la jaula, pero más precisamente en "Perdido", un cuento de Con la otra gente, del '67, y en la novela En vida de 1971. En esta última, el personaje se debatía entre una partida imposible y la elección entre dos espacios, dos mujeres, dos vidas. En Mascaró..., finalmente, parte y con la partida parece encontrar un sentido para la vida, el de la solidaridad. Proceso que, alegóricamente, se da junto a los amigos del Circo del Arca y los pueblos recorridos, y el tiroteo, y la prisión y la tortura, y la recuperación definitiva de la libertad. Obviamente, puede hablarse de un viaje iniciático o/y de un viaje de aprendizaje. ${ }^{5}$

Sin embargo, cste viaje no se reliere sólo a una cuestión de personajes. Mascaró... realiza un cruce, en verdad iniciático, entre escritura y destinos. Como si la escritura, premiada en 1975 por Casa de las Américas en La Habana, adelantara itinerarios de una escritura argentina a la vez que destinos personales.

...mandó encender las luces y el pueblo de Tapado se detuvo por un momento, dejó de envejecer, porque la carpa se iluminó por dentro y todos vieron que era algo hermoso sobre la tierra, aunque no pasara nada más que eso y estuviese allí encendida toda la noche mera figura, a ratos sacudida por una brisa, como si consistiera viva y fuese a remontar vuclo igual que un globo, y todos, tan livianos, depegaran también de aquella tierra dormida bajo la arena y pudiesen ver desde arriba, medio pajaritos, ese agujero en medio del desierto donde habian transcurrido su vida...

... El circo "es" para ellos, aunque de dudosa materia. Mil y mil maravillas, nunca visto. $Y$ siendo, se marcha...

... La arena se desliza en la cavidad de la huella, el viento la empareja. Fue y se fuc. Pero quedan las figuras. Los chicos perinolean, farsetean, carpoforean. Dibujan leones en la arena con la punta de una ramita. Las mujeres se ensonian. Los hombres bembelean. ...

${ }^{5}$ CAMPRA, Rosalba, "Da Los premios di Cortazar a Mascaró. El cazador americano di Conti: il viaggio iniziatico della letteratura argentina" en Sigfrido nell movo mondo. Roma: La Goliardica, 1983. GNUTZMAN, Rita, "Haroldo Conti: de la soledad a la solidaridad" en Cuadernos para la imvestigación de la literatura hispánica (Madrid), n. 13, 1990.

${ }_{7}^{6}$ Mascaró..., op. cit., p. 188.

${ }^{7}$ Jbid., p. 241. 
Son operaciones de tipo lingüístico las que provocan la naturalización del acontecer, me refiero a los procedimientos formales que consiguen el efecto de verosimilitud y, entonces, el pacto de realismo que se establece, a la vez, con el lector en zonas, incluso, mágicas del relato. Simultáneamente, estas operaciones lingüisticas sostienen la posibilidad de contar otra historia, diferida de las historias oficiales. Es decir, los procedimientos de verosimilitud son escriturarios. El discurso social se despliega en las distintas figuras, metonímica, sinecdótica, metafóricamente. Una historia se desplaza en estas trazas. El orden no es arbitrario, sino que hay pliegucs y repliegues, causas y efectos troceados, partirizados (de partitas), fugados en deslizamientos subrepticios hasta llegar a una metáfora, la cual, obviamente, como todas las metáforas, termina hablando de otra cosa. Sin embargo allí no se detiene el movimiento escriturario: la metáfora, en definitiva, se hace multiplicidad, cadena metafórica enganchada por causas y partes, por efectos y presentimientos del todo: lo clandestino. Una cadena metafórica que, finalmente, reside en la alegoria. ${ }^{8}$ El juego de palabras no pretende ser ingenuo.

El objetivo que una retórica desgastada le asigna a las figuras - pensando en la acepción que llegó a tener esta disciplina a fines del siglo pasado y principios de éste - sería el del puro adorno. Aquí, por el contrario, en la escritura de Conti, las figuras resultan ser una operación ideológica. Son las figuras retóricas las que operan sobre la naturalización y el pacto de lectura. Si el lector no puede reconocerlas, reconocerse, no puede entrar en el pacto, y entonces, no puede participar, en sentido metafórico, de la toma de lo abierto que implica el texto de Conti y al que se llega por el mismo movimiento retórico que va de la sinécdoque a la metonimia, a la metáfora y, finalmente, a la alegoría. Pero si el lector no puede reconocerlas es llevado, pedagógicamente, cn esa gradación retórica hasta la alegoria.

Tal como proponían las primeras vanguardias, la alegoría se construye del lado del lector, pero, en este caso, bajo una impronta de naturalización: los materiales no se ofrecen en bruto, sino en una gradación que pasa, precisamente, por las tres etapas retóricas antes mencionadas: sinécdoque, metonimia y metáfora. Si en cl texto se llega a algún lugar se trata de lo abierto, el indefinible espacio de lo abierto que necesita de un relato alegórico para desarrollarse. Un espacio cerrado tiene límites precisos que dicen sus contornos de descripción. El problema en Conti, como en las escrituras del exilio, es cómo dar cuenta del

${ }^{8}$ Para hablar de figura retórica recomiendo mirar Retórica general, del Grupo M (Barcelona: Paidós, 1987) y el más reciente Manual de retórica, de Bice Mortara Garavelli (Madrid: Cátedra, 1991). En cuanto a la "alegoria”, como figura que reúne diversos niveles lógicos - algunos la definen como el encadenamiento de metáforas, y éstas, a su vez, contienen la sinécdoque y la metonimia - es el punto clave del análisis de las escrituras de exilio. Para el tratamiento retórico de la alegoría y sus diferentes refuncionalizaciones, véase el excelente trabajo de Walter Benjamin "Alegoría y Trauerspiel" en El origen del drama barroco alemán (Madrid: Taurus, 1990). 
deslizamiento para llegar a una escritura de lo abierto. Conti parece haberlo conseguido en el desplazamiento retórico. La alegoria de Mascaró... es un desplazamiento permanente: cuando se reconstruye una sinécdoque, resulta una metonimia; cuando se descausaliza una metonimia, resulta una metáfora; cuando se intenta traducir una metáfora, no es una sino un montaje detenido alegóricamente pero, al mismo tiempo, puesto en abismo, sobreimpreso de espejos.

Ha sido dicho varias veces: Mascaró... es una novela alegórica. Pero Conti ha dicho:

... Siempre me refiero a un escenario real: en ese sentido soy realista. Claro que si alguien se tomara el trabajo de desbrozar todo eso, ¿qué coincidencia habria con la realidad? Esa realidad contiene el clima de otra, pero no es un calco [...] Todo requiere un trabajo de punteria y afinación...

Sin duda Conti alude a lo que yo llamo retórica del deslizamiento y que implica un trabajo de despliegue del movimiento alegórico, "punteria y afinación”.

¿Qué significa, entonces, entrar en el pacto? Se ha hablado de un pacto de lectura. Pero hay más: está en ese mismo pacto, el subirse al Arca, recorrer los pueblos, subvertir el orden, ser tomado prisionero, ser torturado, liberarse junto a otros. El pacto radica entre los otros. En la dialéctica, no en la sintesis, en el movimiento metonímico, sinccdótico, metafórico que puede hablar de otra cosa, incluyéndonos para, finalmente, convertirse en alegoría de algo que "Va y va".

Se ha dicho, alegoría de iniciaciones y aprendizajes. Sin duda, digo, pero además, de escrituras y destinos. Libro de navios y borrascas vuclve a cruzar sobre el discurso de su relato el relato alegórico de Mascaró..., y Mascaró... ya habia cruzado otros discursos, propios y ajenos, otros viajes, sobre su viaje, sobre su discurso. Asi, hacia atrás y hacia adelante, sólo cambiando vestidos y asumiendo nuevos nombres, montando el espectáculo del circo que es un "cjército disperso y subversivo".

... El circo iba entre medio de las cabalgaduras pero de lejos figuraba una sola cosa, algo bastante distinto a cuando salieron de Palmares, más que un circo una tropa... ${ }^{10}$

${ }^{9}$ Citado por Liliana Herr en "Homenaje a Haroldo Conti”, Diario Página 12, suplemento especial de la subsecretaria de cultura de la provincia de Buenos Aires, 30 de abril de 1993.

${ }^{10}$ Mascaró..., op. cit., p. 250. 
El tiempo no nos permite más que exponer algunos materiales y hacer una lectura, entre otras posibles: el texto se mueve por partes, por causas y efectos, en definitiva logra la metáfora pero en una cadena metafórica, es decir la alegoría. Se trata de un texto voluntariamente desarraigado, en camino, sostenido en el aire. Se trata, epistemológicamente hablando, de una ruptura en cuanto a otra forma de ver las cosas: un intento más de superación de la autonomía del arte pero, al mismo tiempo, la salvaguarda frente a las dificultades de un montaje en bruto. La literatura, para Conti, no es cuestión de afincamientos, sino de contínuas conspiraciones, de revueltas, no en la violenta acentuación de contradicciones, sino en un aprendizaje por partes, por la comprensión de causas y efectos, finalmente, por la abstracción hasta llegar a un sistema de abstracciones. Allí cl cárácter subversivo, en todo caso, de las figuras de la vieja retórica.

El texto trabaja por sinécdoques y metonimias pero no puede entenderse por partes. Se llega a él en la cadena metafórica, en las diversas alegorías que se realizan en un movimiento de flexión y reflexión. Podria pensarse en teoria y práctica, sin embargo la alegoría implica una praxis sin divisiones, un entrenamiento personalizado y permanente.

Ahora bien, alegorías de qué vuelvo a preguntar. De la literatura, de un movimiento revolucionario, de la liberación, del pacto con los otros, de la toma del aire, de la renuncia a los afincamientos. Pero también, de escrituras por venir y destinos personales: las figuras retóricas puestas en relieve por la escritura de Conti operaran en cierta narrativa posterior. Se trata de operaciones discursivas pero también de destierros, exilios, lo social clandestino, la censura, la desaparición, la narración por lo oblicuo, la estratcgia del cuento naturalizado: la refuncionalización de vicjas figuras retóricas cruzadas sobre la historia. No otro ha sido el mecanismo discursivo de Mascaró... y cierta narrativa posterior que ha tenido que ver con la toma, censurada por supuesto, de lo abierto. "Exilio" scría el concepto crítico operativo de estas escrituras. Y lo que se ha llamado retórica del deslizamiento, con su constitución nueva de sinécdoques, metonimias y metáforas que confluyen en una construcción alegórica, arma las maneras de esa escritura bajo un signo ideológico diferente.

Al decir constitución nueva pienso en la producción de sentido nueva que realizan. No se trata de la decodificación de las figuras en sentido literal, sino de una refuncionalización que reuniria la serie retórica sobre la social y la lógica. Se podría hablar más bien de un proceso de encodificación. Como si una serie sólo pudiese definirse, provisoriamente, por la casilla de otra serie, es decir, la seric retórica por la social, la social por la lógica, la lógica por la retórica, y así sucesiva y simultáneamente, dejando siempre una posibilidad en potencia para que el sentido se arme en una red de escrituras, las escrituras del exilio, en permanente movimiento. Unas remitićndose a otras y a otras y a otras, puestas en abismo dentro de la misma textualidad, armando una historia de la escritura 
dentro de los mismos textos, a partir de elementos que han sido recurrentemente apuntados por las teorías de la literatura pero que, en verdad, no han sido trabajados: esto es, el contenido de las formas como quisieran los primeros formalistas, después Adorno y recientemente Hayden Whitc.

El asalto a lo abierto, como propuesta del texto de Conti tiene que ver con esta posibilidad lógico-retórica, pero entonces también social, por el contenido de las formas.

Finalmente, las formas de la escritura del exilio, fechables a partir de 1976, si se quiere antes y todavía hoy, tienen un momento importante de formación, por lo que significan en cuanto a la producción de sentido, en Mascaró... de Haroldo Conti, un desaparecido. Una paradoja social que se formula en una paradoja lógico-retórica: un juego de lenguaje, en verdad, un dramático juego de lenguaje. La literatura, la escritura, se resiste, hace el juego, citando y citándose, desde dentro de la escritura misma y recuperando, así, los cuerpos, los nombres, los sujetos, por este trabajo de pliegue y despliegue al que nos comprometen refuncionalizadas figuras retóricas.

\section{RESUMEN}

Para trabajar una textualidad particular encuadrable en las "cscrituras del exilio", referidas a las escrituras ocurridas entre 1976 y 1983 en la literatura argentina, es necesario repensar las figuras de la retórica tradicional. A primera vista, esta textualidad puede trabajarse como cualquier otra, sin embargo hay algo que siempre se escapa, se desliza, no se dice o se dice de otra manera. El trabajo intenta apuntar esas otras maneras en Mascaró. El cazador americano, un texto pensado como inicial en el sentido de las escrituras del exilio. Esas maneras tienen que ver con las figuras de la retórica tradicional pero resultan ser, antes que figuras, decorativas si se quiere, operaciones ideológicas.

Palabras clave: literatura argentina del exilio y retórica; Haroldo Conti; Mascaro. El cazador americano.

\section{RESUMO}

Para trabalhar uma textualidade particular, que é possivel ser enquadrada nas "narrativas do exilio" (como as que apareceram entre 1976 1983 na literatura argentina), é necessário repensar as figuras da retórica tradicional. À primeira vista, essa textualidade pode ser trabalhada como qualquer outra; no entanto, existe algo que sempre escapa, desliza, não se diz ou se diz de outra maneira. Este trabalho procura apontar essas outras 
maneiras em Mascaro. El cazador anericano, num texto pensado como inicial no sentido das narrativas do exilio. Essas maneiras têm a ver com as figuras da retórica tradicional, mas representando mais que figuras puramente decorativas, operações lógicas.

Palavras-chave: literatura argentina do exilio e retórica; Haroldo Conti; Mascaro. El cazador americano.

\section{ABSTRACT}

One was to think over traditional rethoric rules when trying to focus on "exile narratives" (such as the ones which were written from 1976 to 1983 in the Argentinian lierature). At first, this textuality may be worked out as any other one, but there is always something escaping, sliding; something which can't be said and so, one sayd it is some other context in another way. This paper tries do show how these other ways in Mascaro. El cazador americano ocrur, in such a text as in the beginning of "exile narratives" these ways are connected with the traditional rethoric rules in purely decorative rules - some logic operations.

\section{REFERÊNCIAS BIBLIOGRÁFICAS}

ADORNO, Theodor. Teoria estética. Madrid: Orbis-Hispamérica, 1973.

DELEUZE, Gilles. Lógica del sentido. Barcelona: Paidós, 1989. . Diferencia y repetición. Madrid: Júcar, 1988.

JITRIK, Noé. "La escritura, los signos y los huecos" [material de Seminario de Actualización Teórica, Maestría en Letras, UNMDP, agosto de 1995].

TODOROV, Tzvetan (comp.). Teoría de la literatura de los formalistas rusos. Bs.As.: Siglo XXI, 1976.

WHITE, Hayden. El contenido de la forma. Barcelona: Paidós, 1992. 